\title{
Childhood Furuncular Cutaneous Myiasis Associated with Seborrheic Dermatitis: A Case Report
}

\author{
Nahda Yaumil* (iD, Anni Adriani, Widyawati Djamaluddin, Safruddin Amin, Sri Vitayani, Dirmawati Kadir, Raja Tina Anggrainy Dwi Putri \\ Department of Dermatology and Venereology, Faculty of Medicine, Hasanuddin University, Makassar, South Sulawesi, \\ Indonesia
}

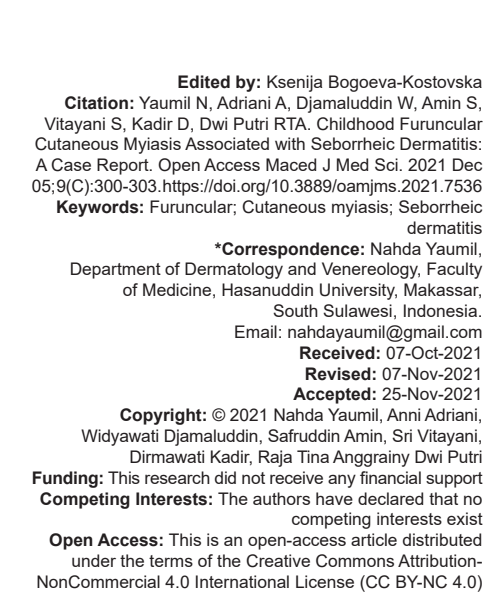

\begin{abstract}
BACKGROUND: Myiasis is a parasitic infection caused by dipterous fly larvae that can affect various organs in both human and animals. Cutaneous myiasis is the most common type of myiasis and can be classified into three categories, localized furuncular myiasis, migratory myiasis, and wound myiasis. One of the risk factors for myiasis is seborrheic dermatitis. The definitive treatment for the condition requires complete extraction of larvae, in combination with oral therapy, and localized occlusion to promote hypoxia. In addition, the larva can be forced to the surface with certain agents.

CASE REPORT: This paper reports a case of a 12-year-old girl with the furuncular cutaneous myiasis associated with seborrheic dermatitis on the occipital region that showed significant improvements after manual extraction of larvae after local anesthesia, in combination with oral and topical therapies. About $2 \%$ lidocaine injections on the base of the lesion and oral albendazole that was given showed efficacy to induce movement of larvae upwards to the surface of the skin and help the extraction process.

CONCLUSION: Cutaneous myiasis is a parasitic infection that can cause significant morbidity and cosmetic issue when left untreated. The definitive treatment of this condition is a combination of manual extraction, oral therapy, and localized occlusion to terminate all the inhabiting parasites. In addition, to ease the extraction process $2 \%$ lidocaine injection and oral albendazole can be given. In younger patients, other conditions such as seborrheic dermatitis can occur in conjunction with this myiasis and should be taken into consideration.
\end{abstract}

\section{Introduction}

Myiasis is a parasitic infection caused by the larvae of flies in Diptera order that affects both human and other vertebrates. The larvae develop and feed either on the living or dead tissue of the host [1]. The disease is endemic in tropical and subtropical areas, with high humidity. One study found that myiasis is the fourth most common travel-related disease [2]. Myiasis can affect various sites of the body and is clinically classified into seven types, based on the body area infested. Cutaneous myiasis is the most common type of myiasis. Other variants include enteric, ophthalmic, auricular, nasopharyngeal, oral, and urogenital. There are three subtypes of cutaneous myiasis, wound myiasis, furuncular myiasis, and creeping dermal myiasis [3]. Various fly species are associated with myiasis, such as those that belong in the Calliphoridae, Sarcophagidae, Hypodermatidae, Oestridae, and Gasterophilidae families. The disease is more prevalent in the tropical areas, and is endemic in Africa and South-East Asia with year-long humidity, and can affect any uncovered parts of the body [4]. Parasitologically, fly-causing myiasis can be divided into three groups, obligatory, facultative, and accidental. Obligatory myiasis is host-dependent and cannot survive living outside the host. The life cycle of this larvae starts as an egg that can be laid either on the hair, skin, or wound. Some examples of this type are the Gasterophilidae fly and a few flies from the Calliphoridae family. As the name suggests, facultative myiasis mostly develops in dead tissue or carrion and can occasionally develop in living tissue, such as Wohlfahrtia magnifica. The last type is accidental myiasis, where a living host accidentally ingests larvae eggs that then develop in the guts [3], [5]. Even though myiasis is a localized condition, chronic condition can lead to significant morbidity and cosmetic issues. Several risk factors are associated with cutaneous myiasis, such as the presence of wound, diabetes Mellitus, seborrheic dermatitis, psoriasis, poor hygiene, and low socioeconomic status [6], [7].

\section{Case Report}

A 12-year-old girl came to the dermatology clinic with the chief complaint of multiple painful small ulcers on her head one week prior. The lesion started 
as two papules that were inflamed and itchy in the past three months. The papules burst and caused bleeding followed with the identification of multiple maggots. In addition, there were yellow scales on the head and the back of both ears with intense itch. The patient lived with her parents in a rural area in Makassar, Indonesia, with poor hygiene and only washes her head approximately twice weekly. Furthermore, she had the habit of playing on the open field. The patient visited the primary healthcare facility and was prescribed with oral antibiotics with no improvement. The patient had a history of recurrent seborrheic dermatitis on her scalp, with no known allergies to food or drugs.

On physical examination, vital signs were within normal limits with adequate nutritional status. The weight of the patient was $53 \mathrm{~kg}$ and her height was $150 \mathrm{~cm}$. Dermatology examination found multiple shallow ulcers with diameters of approximately $0.5-1 \mathrm{~cm}$ on the occipital region along with mild inflammation, excoriation, yellow scales, serosanguineous fluid, and visible larvae (Figure 1a).

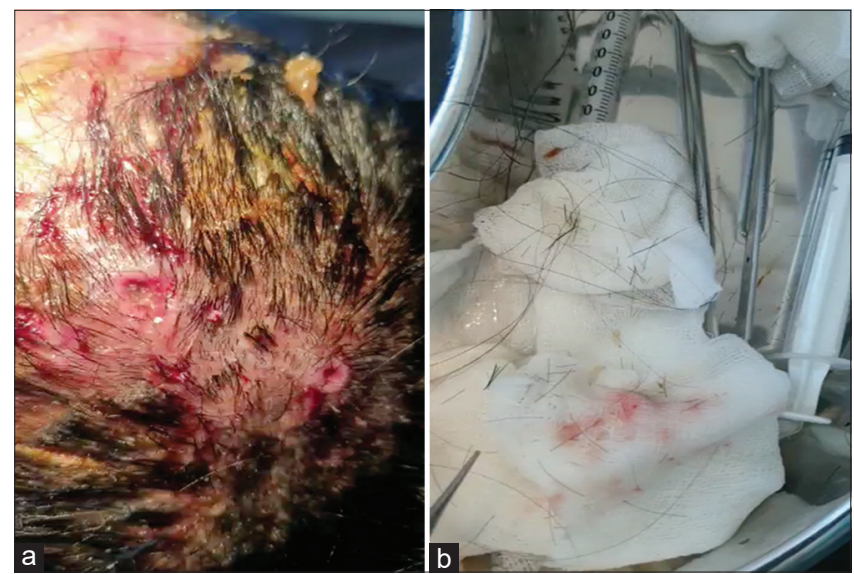

Figure 1: Multiple shallow ulcers with yellow flaking, crusts, bleeding and serosanguinous fluid on the head (a); post manual extraction of larvae after local anesthetic of $2 \%$ lidocaine on the lesions (b)

Working diagnosis of the patient was established as cutaneous myiasis with seborrheic dermatitis. The planned treatment was local anesthesia with $2 \%$ lidocaine injection on the base of the ulcer followed with manual extraction of larvae combined with oral regiment of $500 \mathrm{mg}$ oral cefadroxil twice daily for 5 days, $400 \mathrm{mg}$ oral albendazole single dose daily for 3 days, and $10 \mathrm{mg}$ oral cetirizine. In addition, topical treatment of gentamycin twice daily and combination of miconazole and desoximetasone were given (Figure 1b).

Follow-up after three days showed improvements with cutaneous lesions starting to dry along with reduced pain and itch. A second follow-up after two weeks showed significant improvements with minimal crusts on the head and no visible lesions on the ears (Figure 2a-d).

\section{Discussion}

This paper reports a case of cutaneous myiasis associated with seborrheic dermatitis on a 12-year-old girl. The diagnosis of cutaneous myiasis was made based on the typical clinical appearance. Initially, the lesion started as two small, painful, and inflamed papules that then burst and caused bleeding and formed multiple shallow ulcers. Furthermore, larvae (maggots) were examined to come out of the lesions. The condition is in accordance with furuncular type myiasis that starts as erythematous papules or blisters that range between $1 \mathrm{~mm}-2 \mathrm{~cm}$ that are itchy and painful. The painful sensation in myiasis is due to the larvae penetrating into the skin. Other symptoms include throbbing and feeling of movement under the skin. Usually in the center of the papule is a central pore that is used by the larvae for air circulation [8]. Along the course of the disease, serosanguinous fluid will form during the larvae stage of the parasite. Central pores can be checked by magnifying glass or by observing air bubbles that rise when the affected area is submerged into water. The definitive diagnosis is made by extraction and identification of larvae. However, diagnoses are usually made clinically by typical clinical findings, especially in endemic areas [3], [9]. To help aid the diagnosis, thorough history taking should be made. In this case, history of recurrent seborrheic dermatitis, poor hygiene, and low socioeconomic class are risk factors for cutaneous myiasis. Furthermore, children and infants are more likely to contract myiasis [10].

We suspect myiasis in this patient is caused due to a combination of factors, such as her chronic seborrheic dermatitis, in conjunction with poor hygiene. The constant scratching on the scalp can induce trauma and can be an ideal breeding ground for fly larvae from egg-infested soil or clothing [3], [11].

Treatment of myiasis consists of three general techniques, insecticides to kill the eggs and larvae, localized occlusion to promote hypoxia and subsequent larvae death, and extraction of larvae either by manual extraction or surgery [5]. The use of $2 \%$ lidocaine injection can be used as both anesthetic for extraction preparation and force the larvae move to the surface to ease the process of extraction. Systemic treatment for this patient was $400 \mathrm{mg}$ albendazole once daily for three days, which has proven to be effective to kill the parasite [12]. Another option for treatment is $1 \%$ ivermectin. Oral and topical antibiotics were administered as there were signs of secondary bacterial infection [13]. In addition, one study found that the use of albendazole can also induce movement of larvae upwards to the surface of the skin and help with the extraction process [5], [12]. For practical and compliance reasons, localized occlusion was not 

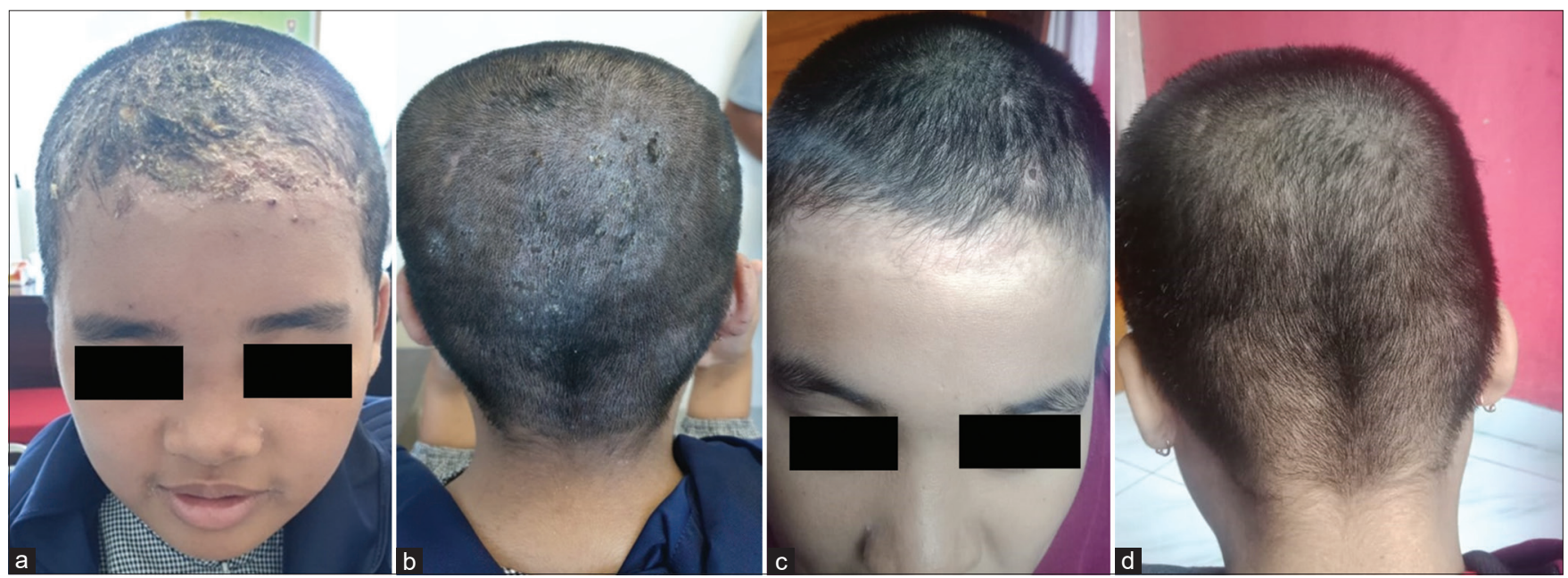

Figure 2: Follow-up post-extraction showed significant clinical improvements after 3 days (a-b) and 13 days (c-d)

applied to this patient due to the impracticality of at least a 24-hour period for occlusion. Usually, manual extraction and oral treatments are sufficient to kill off the parasites. In addition, prolonged occlusion treatment can prompt inflammatory reactions that can worsen the condition [14].

Patient also presented with a yellow scale and crusts on her head, along with a history of recurrent dandruff which were diagnosed as seborrheic dermatitis by its clinical appearance. This condition occurs in the seborrheic areas such as the scalp [7]. Therefore, combination of topical anti-fungal miconazole and corticosteroids were added on the treatment plan, as seborrheic dermatitis is associated with Malassezia furfur. One study found that seborrheic dermatitis is a risk factor for myiasis [3], [14].

A follow-up three days after initial treatments showed improvements with reduced inflammation, less secretion of serosanguinous fluid, and bleeding, leaving only crusts on the scalp and the areas behind the ears. After thirteen days of treatment, the condition is almost resolved, leaving only minimal crusts and no other visible lesions.

\section{Conclusion}

Cutaneous myiasis is a parasitic infection that can cause significant morbidity and cosmetic issue when left untreated. The definitive treatment of this condition is a combination of manual extraction, oral therapy, and localized occlusion to terminate all the inhabiting parasites. In addition, to ease the extraction process $2 \%$ lidocaine injection and oral albendazole can be given. In younger patients, other conditions such as seborrheic dermatitis can occur in conjunction with this myiasis and should be taken into consideration.

\section{Conflict of Interest and Ethics Consideration}

The authors declared no conflict of interest and have acquired written consent from the patient for the data and pictures to be used for publication. The patient's mother has agreed and signed an informed consent form for publication purposes.

\section{References}

1. James WD, Berger TG, Elston DM, Odom RB. Andrews Diseases of the Skin: Clinical Dermatology. Philadelphia, PA: Saunders Elsevier; 2006.

2. Robbins K, Khachemoune A. Cutaneous myiasis: A review of the common types of myiasis. Int J Dermatol. 2010;49(10):1092-8. https://doi.org/10.1111/j.1365-4632.2010.04577.x PMid:20883399

3. McGraw TA, Turiansky GW. Cutaneous myiasis. J Am Acad Dermatol. 2008;58(6):907-26. https://doi.org/10.1016/j. jaad.2008.03.014 PMid: 18485982

4. Imtiaz M, Rahman A, Islam K, Barua M, Alim MA, Chowdhury S, et al. Prevalence and associated risk factors of myiasis in different areas of Chittagong, Bangladesh. Res $\mathrm{J}$ Vet Practit. 2014;2:22-7.

5. Francesconi F, Lupi O. Myiasis. Clin Microbiol Rev. 2012;25(1):79-105. https://doi.org/10.1128/CMR.00010-11 PMid:22232372

6. Mariwalla K, Langhan M, Welch KA, Kaplan DH. Cutaneous myiasis associated with scalp psoriasis. J Am Acad Dermatol. 2007;57(2):S51-2. https://doi.org/10.1016/j.jaad.2006.10.022 PMid: 17637377

7. Kleine C, Schoefer H, Amendt J, Bexten T, Just-Nuebling G. Cutaneous myiasis in a patient with seborrhoeic eczema. Lancet. 2014;383(9921):1012. https://doi.org/10.1016/ S0140-6736(14)60199-9

PMid:24629299

8. Monsel G, Delaunay P, Chosidow O. Arthropods. In: Griffiths C 
Barker J, Bleiker TO, Chalmers R, Creamer D, editors. Rook's Textbook of Dermatology. $9^{\text {th }}$ ed. United States: Wiley; 2016.

9. Caissie R, Beaulieu F, Giroux M, Berthod F, Landry PÉ. Cutaneous myiasis: Diagnosis, treatment, and prevention. J Oral Maxillofac Surg. 2008;66(3):560-8.

10. Ogbalu OK, Achufusi TG, Orlu EE. Epidemiology of human furuncular myiasis of Cordylobia anthropophaga (Grunberg) in Nigeria. International Journal of Dermatology. 2013;52(3):331-6. https://doi.org/10.1111/j.1365-4632.2012.05641.x

PMid:22861528

11. Gontijo JR, Bittencourt FV. Wound myiasis: The role of entodermoscopy. An Bras Dermatol. 2018;93(5):746-8. https:// doi.org/10.1590/abd1806-4841.20188043

PMid:30156632
12. Sunny B, Sulthana L, James A, Sivakumar T. Maggot infestation: Various treatment modalities. J Am Coll Clin Wound Spec. 2016;8(1-3):51-3. https://doi.org/10.1016/j. jccw.2018.03.002

PMid:30276127

13. Pacioni C, Amadori L, Hijazi Raed M, Tosoni F, Ricevuti G. Use of antibiotics for epidermal wounds in emergency room: Correct prophylaxis and right choice of the treatment. Open Emerg Med J. 2013;5(1):25-8.

14. Calderón HP, Rojas EC, Apt BW, Castillo OD. Cutaneous myiasis due to Cochliomyia hominivorax associated with seborrheic dermatitis. Rev Med Chil. 2017;145(2):250-4. https:// doi.org/10.4067/S0034-98872017000200013

PMid:28453592 